\title{
Syntactic Variants of Caused-motion Event
}

\author{
Xiaorong Xia \\ School of Foreign Languages and Cultures, Nanjing Normal University, Nanjing, Jiang Su Province, 210097, China
}

\begin{abstract}
Goldberg (1995) invents several extended senses from caused motion for English caused-motion construction. However, these senses are more related to the senses of verb classes. The extended senses defined in this way would yield more and more diversity, as different classes of verbs are creatively used in the construction. The thesis, basing on the corpus data, aims to devise extended senses from elaboration on the spatial relation between theme and location. The different senses are expressed by syntactic variants, which share the core sense of caused motion while varying in different spatial relation of theme and location. The difference is reflected in syntax by means of different types of prepositions. The senses defined in this way are helpful to probe into the relation between semantics of verbs and their syntactic behavior.
\end{abstract}

Index Terms - caused-motion event, syntactic variants

\section{INTRODUCTION}

Goldberg $(1995,76)$ argues caused-motion construction as a combination of syntactic form NP VNP PP and semantics " $X$ Cause $Y$ to Move $Z$ '. This form may correspond to several other senses, being extended ones of the central sense above. The senses (1i)-(1vi) are exemplified by sentences (1a-1f) respectively.

(1) a. Frank sneezed the tissue off the table.

b. Mary urged Bill into the house.

c. Sue let the water out of the bathtub.

d. Harry locked Joe into the bathroom

e. Sam helped him into the car.

f. Sam accompanied Bob into the room.

i. X CAUSES Y to MOVE Z

ii. The conditions of satisfaction associated with the action denoted by the predicate entail: $\mathrm{X}$ causes $\mathrm{Y}$ to move $\mathrm{Z}$

iii. X ENABLES Y to MOVE Z

iv. X PREVENTS Y from MOVING Z

v. X HELPS Y to MOVE Z

vi. A Further Extension (Agent and theme move along a specified path.)

Though Goldberg (1995) thinks that the central sense and the extended senses combine into a category of related senses that are associated with caused-motion construction, it is not difficult to find that these senses are closely related to certain types of verbs. Except that the central sense is defined with semantic factors such as "manipulative causation and actual movement" (Goldberg, 1995, p. 162), the extended senses are described as related to different classes of verbs. For example, sense (1ii) pertains to force-dynamic verbs that encode a communicative action (e.g. order/ask/invite/beckon/urge/send). They can appear in caused-motion construction only when the conditions associated with actions they denote are satisfied. Sense (1iii) derives from instances with force-dynamic verbs encoding removal of a barrier (e.g. allow/let/free/release). Sense (1iv) refers to, on the contrary to sense (1iii), the imposition of a barrier and relates to verbs like lock/keep/barricade. Sense (1v) involves ongoing assistance to move in a certain direction with the use of verbs like help/assist/guide/show/walk. A further extension pertains to a subclass of verbs whose agent is not the cause, enablement or prevention of motion and whose agent argument and theme argument move along a specified path. Verbs such as accompany/follow/trail/tail fall into this class. Although Goldberg (1995) does not relate the central sense to any class of verbs, we may infer from her examples with push/kick/sneeze/shove that they are force-dynamic verbs denoting the exertion of physical force.

Caused-motion construction is thus polysemous, involving systematically related senses for each class of verbs. That is to say, each extended sense is not only closely related to the central sense but also pertains to certain types of verbs or verbs with certain semantic features. English is a satellite-framed language (Talmy, 2000), so that verbs encode manner while prepositions indicate path. Causation subevent in caused-motion event is normally expressed by verbs denoting different manners of causation. It might be an instantaneous force or a continuous causation. The different senses posited by Goldberg (1995) are just profiles on different manners of the Antagonist opposing the Agonist with respect to force.

However, given different classes of verbs, like verbs of change of state, verbs of contact by impact, motion verbs, etc., occur in caused-motion construction, the manner of causation is not the key factor to caused-motion event; what is more important is that the causer's behaviour is construed as the cause of motion by conceptualizer. Besides force exertion, instrument, manner of motion, and even change of state can be construed as the cause. It is no wonder that other 
constructionists (Kay, 1996, 2002, 2005; Boas, 2003, 2008; Iwata, 2005, 2008) would put more words in verbal constructions.

In comparison, different senses arising from profile on Motion subevent are more rewarding to gain a deeper insight into caused-motion event. The Motion subevent is expressed by prepositional phrases which denote the path of motion. Compared to the numerous verbs that can occur in caused-motion construction, the prepositions are limited. Moreover, prepositions indicate more than path or location; they can express different spatial relations between figure and ground. Even if only path is expressed, the profile on certain part of the path is also diverse. The conceptualizer may only pay attention to source location where the entity is moved away while gapping where it would move. Similarly, the final location can be windowed when the conceptualizer does not care about the previous location or the middle points of the motion.

Basing on corpus data of prototypical caused-motion verbs collected from WebCorp (http://www.webcorp.org.uk/live/) and Corpus of Contemporary American English (CCAE, http://corpus.byu.edu/coca/), the thesis explores six syntactic variants of caused-motion event. They all express caused motion, though different as a result of elaborating the path role in the event. That is, the syntactic variant may indicate different portions on the path of motion; or it expresses an intended goal. The goal can be a person or a location; the theme can be in contact with the goal or not. The variation is reflected by the use of different prepositional types. The position of syntactic variants provides more insight into the fusion of verbs into caused-motion construction, because the variants have connection to certain classes of verbs. The further division of caused-motion construction into six syntactic variants would shed some new light on the research into semantic-syntactic interface.

\section{CAUSED-MOTION EvENT}

Caused-motion event expresses a force-dynamic relation between participants, namely, one participant exerts force on another participant and causes it to change its location. Force dynamics demonstrates how entities interact with respect to force (Talmy, 2000). The focal force entity is the Agonist and the force element that opposes it is the Antagonist. The use of different verbs indicates the cognitive processing of force dynamics. Bang, for example, foregrounds the manner of the Antagonist opposing the Agonist with respect to force, while roll foregrounds the manner of the Agonist's tendency toward action. In comparison, empty shows the resultant state of the force-dynamic relation and funnel foregrounds the instrument used to fulfill the force dynamics.

(2) a. a stick that's used to bang the ball into the hole!

b. Joseph might easily have been able to roll the stone against the entrance by himself

c. Collect a spoonful of colored cold water. Gently empty the spoon on the surface of the uncolored hot water by placing

d. funnel the acids against the lingual surfaces (All are taken from WebCorp.)

The event consists of two subevents: one denotes the manner of causing the motion and the other indicates the motion. A Causer initiates the motion of an Object by means of certain behavior and then the latter moves from Source Location to Final Location (Goal), as seen in Table 1. On the Path, Object in Motion traverses many middle points (Route). Profile on Causation subevent and Motion subevent is supposed to yield more extended senses.

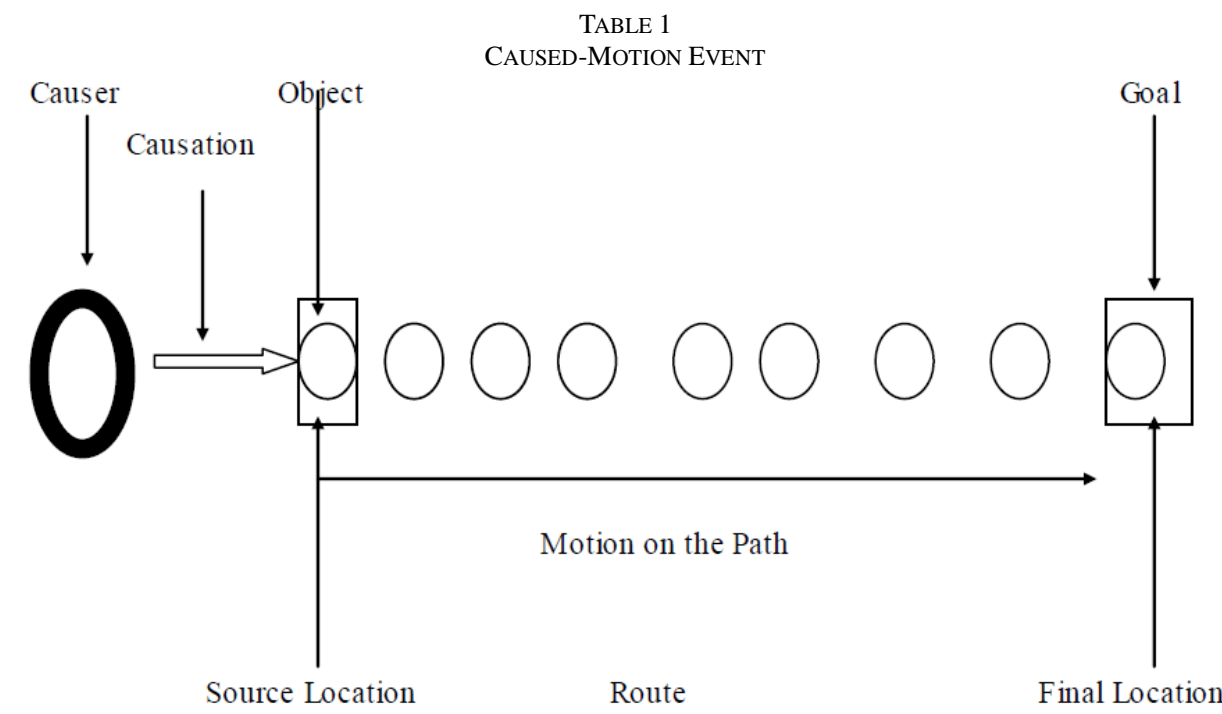

In the process of construal of certain event into a caused-motion one, certain participants can be further elaborated to specify more detailed information, which results in subtle variation in semantics. The difference would also be realized in syntax. The following sentences, despite their prototypical caused-motion sense, elaborate the spatial relation between figure and ground in different views. 
(3) a. I know that if I throw the ball out of the window, it will not break if ...

b. throw coins in the massively theatrical Trevi fountain in the hope of romance

c. If you throw enough staff at the fan, some of it will hit the target.

d. throw my bouquet to one of you at the meeting

e. I threw the ball against the wall.

f. ... throw the puncher off balance. (All are from CCAE.)

(3a) expresses the change of position of the ball because of the throwing action. This is a prototypical caused-motion instance, with a causer initiating the motion of the theme. The ball moves out of the window to somewhere else. (3b), compared to (3a), windows the final position of the entity in motion.

The prepositions used in $(3 \mathrm{c}),(3 \mathrm{~d})$ and (3e) express more than a portion on the path of motion. (3c) with an at-phrase has a conative interpretation. Agent tries to throw something at the fan and wishes some of it may hit the target. But we cannot infer from (3c) whether agent can manage it. Anyway, the throw action has evoked the motion of the staff. In contrast to (3a), the action in (3c) involves an intended target. In (3d), to indicates the direction of motion. In particular, the goal is a person who is supposed to get the entity in motion. Against in (3e) also expresses a special implication. That is, the throwing action not only evokes the motion of the theme to a certain goal, but also causes it to bump onto the goal.

(3f), however, indicates the change of state as well as the change of location. The construal of the spatial relation between figure and ground is different from that in the sentences from (3a) to (3e). Because of the throwing action, the puncher undergoes a change of position, which finally leads to his losing balance. The ground to which the puncher is described in reference is not mentioned syntactically. It might be the floor or something else.

Croft (2009) argues that the spatial relation between figure and ground in caused-motion event is not causal, although the agent causes the change of position. Figure is just conceptualized or construed as antecedent to ground in the "causal" chain. That is, the relation between figure and ground is what we construe. The sentences in (3) show different construal of figure and ground. The speakers of (3a) and (3b) window certain portion of the path of motion, the former windowing the source while the latter windowing the final position. The speakers of the sentences from (3c) to (3f) seem to profile differently on the goal. (3c) reflects the intention of agent to move something to target, (3d) aims at a person target who ought to get the theme, and (3e) profiles the contact between the theme and the goal. (3f) involves change of state arising from change of location. Path is replaced by the description of the final state.

All the sentences involve the throwing action, but the conceptualizers or the speakers pay attention to different aspects of the action and construe it in different ways, which in turn influences the realization in terms of different prepositional phrases. However, the sentences have the same conceptual contents: the throwing action and the prototypical sense of caused motion. They are the syntactic variants of caused-motion event.

\section{SYNTACTIC VARIANTS}

Cheng and Mei (2008) also make an exploration into variants of caused-motion event. Conative variant (4b) and with-variant (4c), similar to location variant (4a), designate the motion of an entity as a result of the agent's action.

(4) a. Tim sprayed the paint onto the wall.

b. Tim sprayed the paint at the wall.

c. Tim sprayed the wall with paint.

(4c) is a causative construction plus a with-phrase. The direct object refers to the entity affected by the material which moves onto it. Different from (4a) and (4b), which profiles the path of caused motion, (4c) profiles the effect of the moved material on its final location. That is, all the surface of the wall ought to be sprayed with paint.

The previous research is based on the corpus data of 25 prototypical caused-motion verbs. The present research would like to include the data of all the caused-motion verbs listed in Levin (1993) and devise six syntactic variants of caused-motion event. The following sections describe the variants in details.

\section{A. Location Variant}

(3a) is the location variant of caused-motion event (Cheng \& Mei, 2008; Cheng, 2010). This variant, paired with the caused-motion sense, is equal to caused-motion construction in Goldberg's constructional grammar and is the prototypical caused-motion variant. The conceptual structure of location variant is described in Table 2.

TABLE 2

CONCEPTUAL STRUCTURE OF LOCATION VARIANT

Causer + Cause $+[$ Object + Location $]$

A causer who initiates the motion and an object which moves are necessary in the conceptual structure of caused-motion event. The conceptualizer of (3a) windows the source of the path.

An open path, according to Talmy (2000), refers to a path described by an object physically in motion in the course of a period of time. Since it is conceptualized as an entire unity, it has a beginning and an end at different locations in space. In the conceptualization, a certain portion of the path may be profiled or windowed while the other parts are gapped. Different windowing patterns of path would result in the profile of different portions of the path. Cheng (2006) 
refines source and goal on the path in terms of location and direction. The prepositions in the following examples express elaboration on the source and the goal.

(5) a. They ran away from behind the building.

b. He walked towards the park.

c. He walked into the park.

d. The money fell on the ground.

In (5a), from designates the source location, away indicates the direction of motion from the source location and behind refers to the location. In (5b), towards expresses the direction of motion to a goal; on in (5d) refers to the final location of motion while into in $(5 \mathrm{c})$ refers to the goal of motion.

Considering the profile on different portions of the path, we would like to describe location variant with the following conceptual structure. Source includes source location and direction of moving away from source location. Route involves the middle points on the path. Direction to goal, goal and final location represent the locative relation between the theme and the goal.

TABLE 3

ELABORATED CONCEPTUAL STRUCTURE OF LOCATION VARIANT

Causer + Cause + [Object + Source/Route/Direction to Goal/Goal/Final Location]

These concepts are realized in syntax by different types of prepositions, source type (from, off and out of), trajectory type (through and across), direction type (to and toward), goal type (onto and into), and locative type (in and on), respectively. Then location variant discussed here has further division in terms of the portion on the path: source location variant, route location variant, direction to goal location variant and goal location variant. Final location indicates the place where the moved entity finally stays. We would list final location variant as a distinct syntactic variant of caused-motion event.

Change of location characterizes location variant. Therefore, the caused-motion verbs indicating motion, rather than resultant state of motion, can occur in location variant. Throw verbs, push/pull verbs and verbs of sending and carrying profile the manner of causation in caused-motion event, while verbs of removing and verbs of putting profile portions on the path of motion, either from a previous position or to a final location. The action denoted by the verbs involves change of location and is similar to caused-motion event. It means location variant is productive for different classes of verbs to participate in.

However, specific semantic features associated with verbs might encourage or prevent the connection between verbs and location variant. In comparison, the verbs specifying the manners of causation are more connected to location variant than the verbs specifying portions of the path of motion. The former appear in different location variants while the latter have bias toward certain variants. Verbs of removing are frequently used in source location variant, and verbs of putting in goal variant and final location variant.

Goal location variant seems to be the most attractive to verbs, considering all verbs, including some verbs of removing, occur with onto or into. The windowing of goal, compared to other portions on the path, is more indicative of the change of position. Anyway, the goal location implies the motion from the initial position through the middle points. Goal location variant accepts different classes of verbs, only if their action relates to change of location.

Source location variant, although closely connected to verbs of removing, also allows the other verbs of caused-motion, including verbs of putting. Anyway, change of position must involve a previous location from which motion begins. Construal in terms of windowing of attention on source or goal of location would connect verbs of removing to goal location variant and verbs of putting to source location variant.

However, within the two classes of verbs, those which are closely associated with the core sense of the class are difficult to participate in other location variants; in contrast, those which specify peripheral factors of the core action are more likely to participate in other location variants. Wipe verbs which relate to manner and instrument of causing the motion are more often found in goal location variant than other subclasses of verbs of removing; similarly, verbs of putting specifying manner, instrument and means occur more frequently in source location variant than those which do not. That is to say, these semantic factors facilitate the construal of connecting verbs to variants.

Route location variant and direction to goal location variant, as the names indicate, involve motion along the middle portions of the path to the goal and directional motion to a goal, respectively. Like goal location variant, they are more connected to verbs specifying different manners of causation, namely, throw verbs, push/pull verbs and verbs of sending and carrying. In contrast, verbs of removing and verbs of putting, which relate to portion on the path of motion, have much fewer occurrences.

\section{B. Final Location Variant}

(3b) is representative of final location variant, which is featured by the use of some locative prepositions like in, on and inside, outside, within, etc.. Goldberg (1995) finds that many prepositions in caused-motion construction have the locative interpretation. Some of the examples are repeated here in (6).

(6) a. Fred stuffed the papers in the envelope.

b. Sam pushed him within arm's length of the grenade.

c. Sam shoved him outside the room. 
d. Sam squeezed the rubber ball inside the jar.

The prepositions in these sentences do no encode a caused-motion sense, neither does squeeze in (6d). In Goldberg's (1995) opinion, it is not necessary for the verbs or the prepositions or their combination to provide the caused-motion sense. It may be attributed to a construction which combines verb and directional preposition. But it is not the case that argument structure construction interprets all verbs in combination with locative prepositions.

(7) a. tug the strings in the tape to form the pleats (From WebCorp)

b. So we helped him schlep the boxes in the snow. (From WebCorp)

The sentences in (7) do not have caused-motion sense; rather, the prepositional phrases indicate the location where the entities denoted by direct objects stay or the location where the action denoted by verbs takes place. Therefore, final location variant is also characterized by motion, or change of location. A certain cause makes the theme moves at the final location. It is important that only the theme finally stays at the location, otherwise the location would become the place where the causing action takes place, as indicated by (7b).

We distinguish final location variant from other location variants, considering the locative prepositions do not indicate the direction of motion as source type, route type, direction type and goal type prepositions do. They predicate low directionality of motion (Rohde, 2001). It is expected that caused-motion argument structure construction would assign the locative prepositions a direction interpretation, just as it does to license some non-caused-motion verbs. However, some verbs, like tug, though fuse into location variants, do not participate in final location variant. Comparatively, locative prepositions do not inherit the motion sense from the argument structure construction as directive prepositions do; on the other hand, more strict limits are set on the verbs used with locative prepositions to express caused-motion event. That is, verbs ought to lexically encode the motion sense or the actions denoted by verbs may at least move something else.

We collect instances of final location variant by excluding those with prepositions which are ambiguous in the reading of location and path. Gehrke (2007) contends prepositions like in, on, under and behind are locative only. Rohde (2001) also posits that at, in, on and under are not dynamic in comparison to onto, into, toward and through, which are highly dynamic. Discussing the connection between verbs and final location variant, we would prefer to collect data of the occurrences of verbs with in and on. The priority of in and on comes from their being more locative. "I bounced the ball under the basketball hoop" and "I bounced the ball behind the defensive", compared to the use of on, are ambiguous in that they have either the locative reading or the path reading. Verbs may have no instances with on or in, but have some with others. For example, no occurrences of drive verbs with in and on have a caused-motion reading; but drive, row and wheel are used with under, drive and cart are used with behind to mean caused motion. Similarly, some carry verbs, which are not found with on or in, can appear with inside or outside to indicate the motion to the final location.

Verbs of goal-oriented motion are more frequently found in the variant. Verbs of putting that occur in the variant imply the release of control on the moved entity near the goal, so that it would safely stay at the designated position. Among the verbs, funnel verbs, which involve instruments in the action, have less connection to the variant. Throw verbs, likewise, are partly found in the variant. We attribute it to the use of instrument and the exertion of instantaneous force, respectively, which do not have objects at the final location as safely as the control of force until they are near the final location.

Continuous causation encoded in verbs of sending and carrying result in the less appearance of these verbs in the variant. In the carrying action, as well as the pulling action, the locative prepositions indicate the final position where the actor and the carried both stay. Final location variant, however, involves only the carried at the final location. The profile on change of state as a result of motion and iterative contact of hands or instruments with the acted prevents clear verbs and wipe verbs from connection to final location variant. Other verbs of removing, profiling motion from the source, are not found in the variant.

\section{Conative Variant}

The previous research of conation is related to intransitive construction (Levin, 1993; Goldberg, 1995). Broccias (2003) defines allative schema and ablative schema of the construction. The allative schema corresponds to Levin's analysis of the conative as an "attempted action". It denotes the emission of a force (which may be metaphorically construed) towards a goal, but the forceful contact is not linguistically encoded and thus backgrounded. As seen in (8a), because of the force from the throw action, the stone moves toward the target.

(8) a. Sally threw the stone at Sam. (Broccias, 2003, p. 309)

b. The horse pulled at the cart. (Broccias, 2003, p. 304)

The ablative schema is associated with continuous actions, either because it is repeated (i.e., in a bit-by-bit manner) or because one single instance of the action is prolonged, and attempted movement (either liberal or metaphorical) of an entity. This schema is similar to the allative schema, in that it also incorporates a notion of attempt. However, this attempt does not apply to the verbal event itself but rather to its expected or desired consequences. In other words, some action is performed upon an entity in an attempt to bring about some result. In ( $8 \mathrm{~b})$, the horse acts on the cart and the latter moves as a result.

The previous research on conative construction summarizes the semantic features including attempted action (Levin, 1993), intended-result, motion, contact (Goldberg, 1995), continuous actions and attempted movement (Broccias, 2003). 
Conative variant of caused-motion event share some features with what have been mentioned above. Firstly, it has an intended-result, namely, an intention of moving something to hit the target. The sentence (3c) has the similar syntax to location variant and indicates the caused motion of the theme, as well. The difference between them lies in the use of prepositions: only at can appear in conative variant, which denotes that the goal of the caused motion is an intention. Cheng (2010) argues that it is an intentional goal in comparison to an actual goal in location variant. That is, the causer intends the moved entity to reach the goal.

The difference can also be described in the conceptual processes of the two spray sentences.

(9) a. Tim sprayed the paint onto the wall.

b. Tim sprayed the paint at the wall.

TABLE 4

CONCEPTUAL PROCESSES OF SPRAY SENTENCES (CHENG, 2010)

\begin{tabular}{l}
\hline Tim sprayed the paint onto the wall. \\
\hline Causer $_{\text {Tim }}+$ Cause $_{\text {spray }}+$ tendency \\
\hline Tim sprayed the paint at the wall. $_{\text {pain }}+$ Goal Location $\left._{\text {onto the wall }}\right]$ \\
\hline Causer $_{\text {Tim }}+$ Cause $_{\text {spray }}+$ intention $_{\text {Object }}$ paint \\
\end{tabular}

In (9a), the causer initiates the motion of the paint, which moves onto the goal. The causer's action manages to move the paint to an actual goal. The tendency consists with the result the causer aims to achieve. In (9b), however, intention takes the place of tendency, showing that the change of location is intended but may not be fulfilled; the goal is just an intentional one, or an intended-result. The difference between an intentional goal and an actual goal results in different postconditions. With an intentional goal, the final result of the motion may conform to the intention or not. So in (9b), the paint may finally fall onto the wall or the agent might miss the target.

Secondly, conative variant encodes forceful motion. Different from intransitive conative construction, the causer's action on the moved entity in conative variant is not continuous; instead, it is an onset force which aims to trigger an attempted movement along a path, though the path can not be imagined since at is not indicative of it. In comparison to location variant, conative variant relates more to an estimated contact of the moved entity with the intentional goal, which in turn indicates there must be some distance between the causer, or the moved entity, and the target. In addition, only the moved entity is intended to hit the target.

The limitations make conative variant the least attractive among syntactic variants of caused-motion event. Among typical caused-motion verbs, only throw verbs have a stronger connection to the variant, which simply indicates that instantaneous causation of ballistic motion over a distance is necessary for verbs to occur in conative variant. At-phrase used with other verbs is more locative, but not directional.

\section{Transfer Variant}

The syntactic structure of (3d) is similar to that of prepositional dative construction, which has some semantic similarity to ditransitive construction. The dative construction profiles the process of transfer whereas the ditransitive construction indicates successful transfer. To in (10b) speaks of the path of the transfer.

(10) a. I gave him a book. (ditransitive)

b. I gave a book to him. (dative)

Some verbs that are conventionally used in caused-motion construction have ditransitive/dative alternation, as well. For example, throw and send occur in the pair in the following sentences.

(11) a. I threw him a book. (ditransitive)

a' I threw a book to him. (dative)

b. I sent him a book. (ditransitive)

b' I sent a book to him. (dative)

In Goldberg's (1995) analysis, the sentences in (12) are defined as instances of transfer-caused-motion construction while the sentences in (13) are treated as instances of caused-motion construction.

(12) a. The judge awarded custody to Bill.

b. Bill gave his house to the Moonies.

(13) a. Sally threw a football to him.

b. Sally handed a scented letter to him.

Compared to the football and the letter in (13) which undergo literal motion, the custody and the house in (12) do not literally move from their previous possessors to the present owners. The two sentences in (12) are motivated by the metaphor that Transfer of Ownership as Physical Transfer; therefore, transfer-caused-motion construction is metaphorical extension from caused-motion construction and is semantically synonymous with ditransitive construction.

Pinker (1989), Pesetsky (1995), Krifka (2004), Rappaport Hovav \& Levin (2008) have the same idea that sentences like (13) instantiate caused motion. The difference between (12) and (13) lies in the fact that to-phrase in (13) denotes both caused motion and caused possession, while in (12) there is only one possibility, namely, caused possession.

We would like to treat (13), similar to (3d), as a different variant of caused-motion event, namely, transfer variant. The transfer variant we discuss here is limited to the use of verbs in caused-motion construction, such as (13), which 
expresses the sense that a causer initiates the motion of an entity toward somebody who is expected to receive it. The variant has something in common with prototypical caused-motion construction (namely, location variant), in that both express the sense that objects change their position. The difference lies in that location variant focuses more on the process of physical movement while transfer variant denotes both the movement and possession transfer.

TABLE 5

CONCEPTUAL PROCESS OF THROW MY BOUQUET TO ONE OF YOU AT THE MEETING throw my bouquet to one of you at the meeting

Causer + Cause $_{\text {throw }}+$ intention $_{\text {[Object }}$ bouquet + Possessor Goal Location to you $]$

Causer intends that Object moves right in the direction of Possessor Goal Location so that Goal Possessor would receive it. Transfer variant is similar to conative variant in that both have an intentional target. But it is supposed that Goal Possessor would finally receive Object. Additionally, Object must have changed from its source location to goal location. The transfer implication is derived from an elaboration of goal into a possessor goal.

The distinction between transfer variant and location variant, conative variant is the actualization of the goal in the event. In transfer variant, the animacy of the goal is elaborated in order to specify the intentional possessive relation between the moved entity and the goal. The intentional possessor is construed as goal location via the metonymy of $A$ Person for A Position to which an object can be located (Kodama, 2004). The causer who initiates the motion is also construed as the previous owner at a certain moment.

Whether the object after to is a recipient of the moved entity or not, it is not completely determined by the animate feature of the prepositional object. An animate can be construed as a destination and a location can be construed as a recipient, as well.

(14) a. John sent the package to Mary.

b. John sent the package to New York.

c. Peter threw the ball to Tom.

d. Peter carried the box to Tom.

Although New York in (14b) is not an animate recipient, the sentence is likewise a good example of transfer varian. Since the verb send is definitely one of the verbs of giving, the to-phrase used with it must imply an intended recipient (Kodama, 2004). New York implies someone in the city by means of metonymic inference. Actually, the recipient reading of the to-phrase is related to the verbal sense.

A place can work metonymically as a recipient, and a person can similarly represent a location through metonymy. Tom in (14c) is not only a place where the ball stops but also an intended recipient. A metonymic inference is made from (14c) so that Tom can designate a locative goal. In contrast, Tom in (14d), or where Tom stands, only represents a locative goal of the box. To caused-motion verbs like throw and carry, whether a recipient reading is derived from the to-phrase is not determined crucially by the noun phrase of a person or a location, but rather by event construal. That is, a locative noun might be construed as a recipient, or vice versa (Kodama, 2004, p. 51).

Therefore, event construal figures in the transfer interpretation of the prepositional phrases. Since transfer variant relates to change of location and change of possession, verbs predicating both are best connected to the variant. Send verbs and steal verbs are such verbs. Most caused-motion verbs only predicate change of location. It means whether the to-phrase used with the verbs has a transfer reading, the manner of causing motion encoded by the verbs counts a lot.

\section{E. Contact Variant}

As the sentence (3e) shows, the entity in motion may run into some obstacles. The ball comes in contact with the wall when it moves.

TABLE 6

CONCEPTUAL PROCESS OF I THREW THE BALL AGAINST THE WALL.

\begin{tabular}{l} 
I threw the ball against the wall. \\
\hline Causer $_{I}+$ Cause $+\left[\right.$ Object $_{\text {ball }}+$ Contact Goal \\
against the wall $]$
\end{tabular}

In the conceptual process of (3e), the throwing action not only results in the motion but also brings the theme into contact with an obstacle, which is described as Contact Goal. We consider (3e) as a variant of caused-motion event because the contact is a natural result of the caused motion. That is, the moved entity changes its position by moving closer to the obstacle and comes into contact with it. The contact between the moved entity and the goal is specified. Contact variant is characterized by the physical contact.

According to Levin (1993), throw does not undergo with/against alternation as hit does.

(15) a. Brian threw the stick against the fence.

b. *Brian threw the fence with the stick.

c. Brian hit the stick against the fence.

d. Brian hit the fence with the stick.

The verbs undergoing the alternation mean that an agent moves an instrument into contact with a target. In the case of throwing the stick against the fence, the stick acts as theme more than instrument. The difference comes from the different senses of verbs: the throwing action naturally involves the motion, while the hitting action does not. What is 
hit may or may not be affected. But the instrument used to hit the target is supposed to change its position from its previous position to the surface of the target. The trajectory of motion in the hitting event is less profiled than that in the throwing event. (15a) and (15c) are similar in that motion takes place before contact. (16), however, presents a different case.

(15) He hit the ball into the outfield.

First, different from (15c), motion in (16) takes place after contact. Or put it more exactly, the motion event in (16) extends from a previous event consisting of the motion of certain instrument and its contact with the ball. The previous event coincides with the event expressed in (15c). (16) is more similar to (15a), since the hitting action, like the throwing action, evokes motion. As a result, a trajectory of motion is obvious.

The examples discussed above involve the contact by impact as a result of forceful motion, thus force is necessary to trigger the motion. The verbs hit and throw encode force exertion on something else. Force exertion, forceful motion and physical contact by impact combine into semantic features of contact variant of caused-motion event. Motion along a path seems to be optional, given that the path is not clear in the case of waving the stick in order to hit the fence.

Caused-motion verbs encoding instantaneous causation are better connected to the variant, since this manner typically results in forceful motion which is prone to make the entity into contact with something by impacting it. Continuous causation of accompanied motion is not an advisable condition for motion to contact something, considering the causer would try best to avoid moving himself into contact by impact with the goal. Iterative contact predicated by wipe verbs only adds to the sense of contact when the verbs are used with against.

\section{F. Causative Variant}

In English, denominalization enables some nouns to be used as verbs to express caused-motion event (Cheng, 2006). Look at the following examples.

(17) a. Sindy buttered the bread.

b. Larry pocketed the money

The denominalized verbs are not supposed to designate some action; rather, butter is the moved entity while pocket is the final position where money stays. The conceptual contents expressed by the action denoted by butter and pocket are similar to those in (18).

(18) a. Sindy put the butter on the bread.

b. Larry put the money into the pocket.

TABLE 7

CONCEPTUAL PROCESSES OF SINDY BUTTERED THE BREAD AND SINDY PUT THE BUTTER ON THE BREAD.

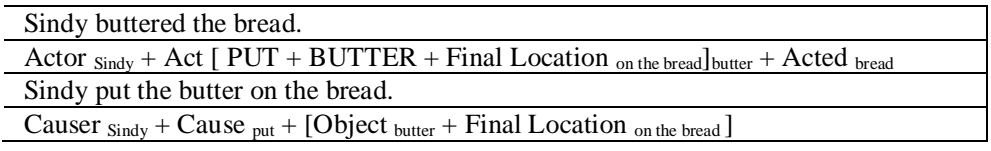

The action of "butter something" is similar to the action of "put butter on something". The summary scanning of the event of putting butter on something would make conceptualizer construe it as a buttering action, which is realized into syntax as (17a). In contrast, the sequential scanning of the putting event would activate the causative location conceptual structure, which is realized in syntax as (18a).

Compared with (18a), the causative variant (17a) omits the process of motion whereas directing attention to a causative effect, or the final state brought about by the motion. Namely, the whole surface of bread is buttered. In contrast, the putting action is accomplished once the first brush of butter on the bread is done. The schema of causative variant only profiles the effect of causation in the whole caused-motion event. The bread in (17a), therefore, is affected by the buttering action and changes its state. It is absent in the conceptual process of the corresponding (18a).

Although the syntactic pattern of causative variant is different from that of other variants discussed above, they have something in common that they encode caused-motion event. The different expressions from the same conceptual contents are due to construal by means of elaborating different participants in the event. Prototypical caused-motion variants elaborate the relation between the entity in motion and the referential location; causative variant, however, only elaborates one of the two participants, either the entity in motion or the referential location. In this sense, the previous five syntactic variants are variants of caused-motion construction.

As Cheng (2006) points out, butter and pocket are used as verbs in syntax, but in the conceptual structures they just represent a participant in the event. For example, butter in the conceptual process of (16a) is Acted while pocket in that of (16b) is Location.

TABLE 8

CONCEPTUAL STRUCTURES OF BUTTER EVENT AND POCKET EVENT

Actor + Act [PUT + BUTTER +Final Location $\left._{\mathrm{i}}\right]_{\text {butter }}+$ Acted $_{\mathrm{i}}$

Actor + Act $\left[\right.$ PUT + Acted $_{i}+$ IN POCKET $_{\text {pocket }+ \text { Acted }_{i}}$

The denominal verbs butter and pocket are the so-called locatum verb and location verb (Clark \& Clark, 1979). We would like to differentiate (17a) and (17b) as instances of locatum-causative variant and location-causative variant. The 
locatum-causative variant has a further extension when the location occurs as direct object while the locatum appears as object of preposition.

(19) a. John loaded bricks onto the wagon.

b. John loaded the wagon with bricks.

(20) a. John cleared the dishes from the table.

b. John cleared the table of the dishes.

The verbs in (19) and (20) have locative alternations. In the projectionist view, alternations result from projection from argument structure of verb. The sentences in each pair present different semantic structures. (a) sentences have the semantic roles of agent, theme and goal while (b) sentences have the roles of agent, patient and material. In Goldberg's (1995) analysis, argument structure construction avoids polysemy of the two verbs. That is, the semantic structures are inherited by the verbs from the two constructions, respectively.

Each pair expresses the same caused-motion event; the sentences of each pair differ in that they profile different aspects of the event, thus present different syntactic structures. Location variant profiles the motion of objects in reference to the location while causative variant foregrounds the final state of referential location while backgrounding what is moved. The moved objects can occur in the instances with prepositions with or of, which would be regarded as extension from locatum-causative variant. We would like to name the extension as with/of-causative variant.

Verbs that profile the resultant state from motion, rather than the motion itself (namely, change of location), are more likely to occur in causative variant. Pelt verbs, butter verbs, pit verbs, debone verbs, fill verbs and spray/load verbs imply the motion brings about some effect, either the impact or the holistic effect on the location. They are more frequently found in causative variant.

\section{CONCLUSION}

The thesis devises six syntactic variants of caused-motion event in order to probe further into the relation between verbs and caused-motion construction. An argument structure construction is supposed to license different classes of verbs in the construction; however, not all the typical caused-motion verbs have the same behavior. The position of six syntactic variants gives a fresh insight into the relation between semantics of verbs and their syntactic behavior. The syntactic variants arise from construal in terms of elaboration on the relation between theme and location. Intention in aiming theme at goal or in contact with goal, or into personal reception, and resultant state of location as a result of theme's motion, besides spatial relation, should also be taken into consideration. These different senses from caused motion result from construing caused-motion event by means of elaborating participants into more detailed information. The corpus data show that the variants attract verbs of different classes with different semantic features. The individual verbs encode something specific in their lexical senses encouraging or preventing the connection between verbs and variants. That is, verbs with similar semantic feature to a certain syntactic variant occur more frequently in it. The division into six syntactic variants provides some light into the relation between verbal semantics and syntactic structures. The extended senses from the six syntactic variants are more sensible than those defined in terms of verbal senses.

\section{REFERENCES}

[1] Boas, H. C. (2003). A lexical-constructional account of the locative alternation. In L.Carmichael, C.-H. Huang \& V. Samiian (Eds.), Proceedings of the 2001 Western Conference in Linguistics, Vol. 13, 27-42.

[2] Boas, H. C. (2008). Resolving form-meaning discrepancies in Construction Grammar. In J. Leino (Ed.), Constructional Reorganization. Amsterdam/Philadelphia: John Benjamins Publishing Company, 11-36.

[3] Broccias, C. (2003). The English change network. Berlin: Mouton de Gruyter.

[4] Cheng, Qilong. (2006). Conceptual fame and cognition. Shanghai: Shanghai Foreign Language Education Press.

[5] Cheng, Qilong. (2010). Conceptual frame and morphosyntactic variants. Speech delivered in Wuhan University of Science and Technology.

[6] Cheng, Qilong \& Mei Wensheng. (2008). Caused-motion events and their clauses. Foreign Language Research, 3, 82-88.

[7] Clark, E. \& H. Clark. (1979). When nouns surface as verbs. Language, 55, 767-811.

[8] Croft, W. (2009). Force dynamics and directed change in event lexicalization and argument realization. http://www.unm.edu/ wcroft/Papers/Montreal600.pdf (accessed 13/05/2009).

[9] Gehrke, B. (2007). On directional readings of locative prepositions. Proceedings of ConSOLE XIV: 99-120. http://www.hum2.leidenuniv.nl/pdf/lucl/sole/console14/console14-gehrke.pdf (accessed 04/12/2012).

[10] Goldberg, A. E. (1995). Constructions: A construction grammar approach to argument structure. Chicago and London: The University of Chicago Press.

[11] Iwata, S. (2005). The role of verb meaning in locative alternation. In M. Fried \& H. C. Boas (Eds.), Grammatical constructions. Amsterdam/Philadelphia: John Benjamins Publishing Company, 101-118.

[12] Iwata, S. (2008). Locative alternation: A lexical-constructional approach. Amsterdam/Philadelphia: John Benjamins Publishing Company.

[13] Kay, P. (1996). Argument structure: Causative ABC constructions. http://www.icsi.berkeley.edu/ kay/bcg/5/lec05.html (accessed 18/12/2006).

[14] Kay, P. (2002). Patterns of coining. http://www.icsi.berkeley.edu/ kay/coining.pdf (accessed 08/03/2008). 
[15] Kay, P. (2005). Argument structure constructions and the argument-adjunct distinction. In M. Fried \& H. C. Boas (Eds.), Grammatical constructions. Amsterdam/Philadelphia: John Benjamins Publishing Company, 71-98.

[16] Kodama, K. (2004). The English caused-motion construction revisited: A cognitive perspective. Papers in Linguistic Science, $10,41-54$.

[17] Krifka, M. (2004). Semantic and pragmatic conditions for the dative alternation. Korean Journal of English Language and Linguistics, 4, 1-32.

[18] Levin, B. (1993). English verb classes and alternations. Chicago and London: The University of Chicago Press.

[19] Pesetsky, D. (1995). Zero syntax. Cambridge, MA: MIT Press.

[20] Pinker, S. (1989). Learnability and cognition: The acquisition of argument structure. Cambridge, MA: MIT Press.

[21] Rappaport Hovav, M. \& B. Levin. (2008). The English dative alternation: The case for verb sensitivity. Journal of Linguistics, 44, 129-167.

[22] Rohde, A. (2001). Analyzing path: The interplays of verbs, prepositions and constructional semantics. Ph. D. dissertation, Bell \& Howell Information and Learning Company.

[23] Talmy, L. (2000). Toward a cognitive semantics (Vol. I and Vol. II). Cambridge, MA: MIT Press.

Xiaorong Xia was born in Nanjing, Jiang Su Province, China in 1973. She received her M.A. degree in linguistics in Central South University, Changsha, Hu Nan Province, China, 2001. She is currently studying for Ph. D degree in Linguistics in Nanjing Normal University, Nanjing, Jiang Su Province, China.

She is a lecturer in School of Foreign Languages and Cultures, Nanjing Normal University, Nanjing, Jiang Su Province, China. Her research interests include theoretical linguistics, cognitive linguistics and semantics. 